九州大学学術情報リポジトリ

Kyushu University Institutional Repository

\title{
Studies on the Roles of Quinone Reductase and the Reductones in an Enzymatic Browning Reaction
}

Nomura, Danj i

Laboratory of Food Technology and Food Chemistry Institute, Faculty of Agriculture, Kyushu University

Hatanaka, Chiaki

Laboratory of Food Technology and Food Chemistry Institute, Faculty of Agriculture, Kyushu University

Omura, Hirohisa

Laboratory of Food Technology and Food Chemistry Institute, Faculty of Agriculture, Kyushu University

https://doi.org/10.5109/22840

出版情報：九州大学大学院農学研究院紀要. 17 (3/4)，pp.313-325，1973-10. Kyushu University バージョン：

権利関係 : 
J. Fac. Agr., Kyushu Univ., 17, 313-325 (1973)

\title{
Studies on the Roles of Quinone Reductase and the Reductones in an Enzymatic Browning Reaction
}

\author{
Danji Nomura, Chiaki Hatanaka and Hirohisa Omura \\ Laboratory of Food Technology and Food Chemistry Institute, \\ Faculty of Agriculture, Kyushu University, Fukuoka
}

(Received June 19, 1973)

\begin{abstract}
Quinone reductase was prepared from white potato. In the presence of NADH, this enzyme reduced two active substituted quinones, quinone-N-acetylcysteine and menadione-N-acetylcysteine, which were produced as the model substances in an enzymatic browning reaction.*

Furthermore, this enzymatic reduction rate was accelerated by pretreatment of the substituted quinones with reductones, such as triose reductone, ascorbic acid, 5-methy -3, 4-dihydroxytetrone, dopa and epinephrine, but not accelerated by pretreatment of the quione reductase with the reductone.
\end{abstract}

\section{INTRODUCTION}

In connection with the function of polyphenol oxidase, a large number of studies on the browning reaction have been reported in many plant tissues, such as tea (Sanderson, 1964), apples (Hulme, 1958), peaches (Reyes and Luh, 1960), grapes (Bayer et al., 1957), bananas (Palmer, 1963), tomatoes (Gladilovich and Drel, 1965) and potatoes (Pate1 and Zucker, 1965). On the other hand, the participation of quinone reductase in the browning reaction, which catalyze the reverse reaction of polyphenol oxidase, has also been reported (Wosilait and Nason, 1954b). Practically, these reductase were purified from white potato (Wosilait and Nason, 1954a; Wosilait et al., 1954b) and spinach leaves (Lazzarini et al., 1964). And the relationships between browning reaction and these quinone reductases were discussed. In addition, the interaction between polyphenol oxidase and quinone reductase were reported recently (Bruemmer and Roe, 1970).

In the previous papers, we obtained as crystalline form the substituted quinones by $\mathrm{N}$-acetylcysteinyl group, such as quinone- $\mathrm{N}$-acetylcysteine and menadione-N-acetylcysteine (Hatanaka et al., 1972a, 1972b). As a means for undrstand ing the browning reaction, we considered about the possibility of participation of these substituted quinones in the browning reaction, because the substituted quinones might be able to occur by the substitution reaction between polyphenol

* Following abbreviations are used in this paper.

p-BQ: p-Benzoquinone, QNAC : Quinone-N-acetylcysteine, MQ : Menadione, MQNAC : Menadione-N-acetylcysteine, $\alpha-\mathrm{NQ}: \alpha$-Naphthoquinone, ASA : Ascorbic acid, MDT: 5-Methyl-3, 4-dihydroxytetrone, EP : Epinephrine, DP :Dopa, NAC : N-acetylcysteine, GL : Glutathione. 
oxidase-generated quinones and SH-compounds, such as cysteine, glutathione and so on, which exist together in vivo (Mason, 1955 ; Mason and Peterson, 1965).

This paper deals with the funetion of quinone reductase and reductones in the browning reaction of white potato.

\section{MATERIALS AND METHODS}

Cell-free extracts of potatoes Three hundred $g$ of peeled potato tuber was blended with one-third volume of cold $0.1 \mathrm{M}$ phosphate buffer ( $\mathrm{pH} \mathrm{7.5)} \mathrm{in} \mathrm{a}$ Waring blender for 2 minutes at $5^{\circ} \mathbf{C}$. The blend was passed through four layers of cotton cloth by hand in order to remove the coarse materials.

The fluid was then centrifuged at $5000 \mathrm{rpm}$ for 15 minutes at $0^{\circ} \mathrm{C}$. Obtained turbid browning solution was used for further purification.

Determination of enzyme activity Reductase activity was measured at $25^{\circ} \mathbf{C}$ by a Hitachi-Parkin-Elmer model 139 spectrophotometer. At this method, the oxidation of $\mathrm{NADH}$ by reductase was followed by the decrease in optical density at $340 \mathrm{~m} \mu$. Standard assay mixtures $(3 \mathrm{ml})$ contained the following :0.6 $\mu$ moles of quinones, 270 moles of potassium phosphate buffer (pH6.5), $0.43 \mu$ moles of $\mathrm{NADH}$ and $0.15 \mathrm{ml}$ of enzyme preparation. The reaction was started by the addition of quinone. The non-enzymatic rate was also determined at $340 \mathrm{~m} \mu$ as described above, except that the enzyme was omitted from the reaction mixture. One unit of quinone reductase is the amount of enzyme that results in a change in OD value of 0.001 per minute, corrected for the non-enzymatic rate. The specific activity was expressed as units per mg protein.

Determination of protein concentration The protein concentration of the various enzyme fractions was measured by Folin phenol reagent method of Lowry et al. (1951), and the concentration was expressed as $\mathrm{mg}$ of egg albumin.

Reagents NADH of purity above 95 per cent was obtained from Kyowa Hakko Kogyo Co., LTD. Dehydroascorbic acid was kindly supplied by Fuso Chemical Company. Triose reductone and 5-methyl-3,4-dihydroxytetrone were prepared according to the method of Euler et al. (Nomura and Omura, 1969). QNAC and MQNAC were prepared by the method described before (Hatanaka et al., 1972a, 1972b). And all other reagents were purchased from Wako Chemical Co., unless otherwise indicated.

Gel filtrationon Sephadex G-75 Five $\mathrm{ml}$ of the enzyme solution was applied to a Sephadex G-75 gel column $(2 \times 75 \mathrm{~cm})$ equilibrated with $0.1 \mathrm{M}$ phosphate buffer ( $\mathrm{pH}$ 7.5). Elution was performed with the same buffer at $5^{\circ} \mathrm{C}$ and $5 \mathrm{ml}$ fractions were collected at a flow rate of $10 \mathrm{ml} / \mathrm{hr}$.

\section{Polarographic method}

a) Experimental apparatus : A Yanagimoto Model 105 Polarograph was used to obtain the current-voltage curves. The electrolytic solution which consisted of $0.1 \mathrm{M}$ phosphate buffer ( $\mathrm{pH}$ 6.5) and a small portion of $\mathrm{N}-\mathrm{KNO}$, was used in these studies. All half-wave potential measurements were made by using the saturated calomel electrode as the reference electrode. 
b) Po'arographic procedure : A half $\mathrm{ml}$ of $\mathrm{N}-\mathrm{KNO}$, was added to $5 \mathrm{ml}$ of 0.25 mM MQNAC dissolved in 0.1 M phosphate buffer ( $\mathrm{pH}$ 6.5). The solution was degassed with high purity nitrogen for 5 minutes, subsequently $1.2 \mathrm{ml}$ of 0.5 $\mathrm{mM}$ reductones dissolved in $0.1 \mathrm{M}$ phosphate buffer ( $\mathrm{pH}$ 6.5) was added. The mixed solution was again degassed, and a polarogram of the sample was recorded. Since menadione and a-NQ were almost insoluble in water, they were dissolved in isopropanol and other procedures were the same as in the case of MQNAC.

\section{RESULTS AND DISCUSSION}

\section{Purification of quinone reductase}

The purification procedure of Wosilait et al. (1954a) from pea seedlings was used with some modifications as shown in Fig. 1. Alumina gel supernatant (FR V) was further purified by Sephadex G-75 gel filtration and the pooled fractions of fraction number 9 to 13 were stored at $-10^{\circ} \mathrm{C}$ and used as a highly purified

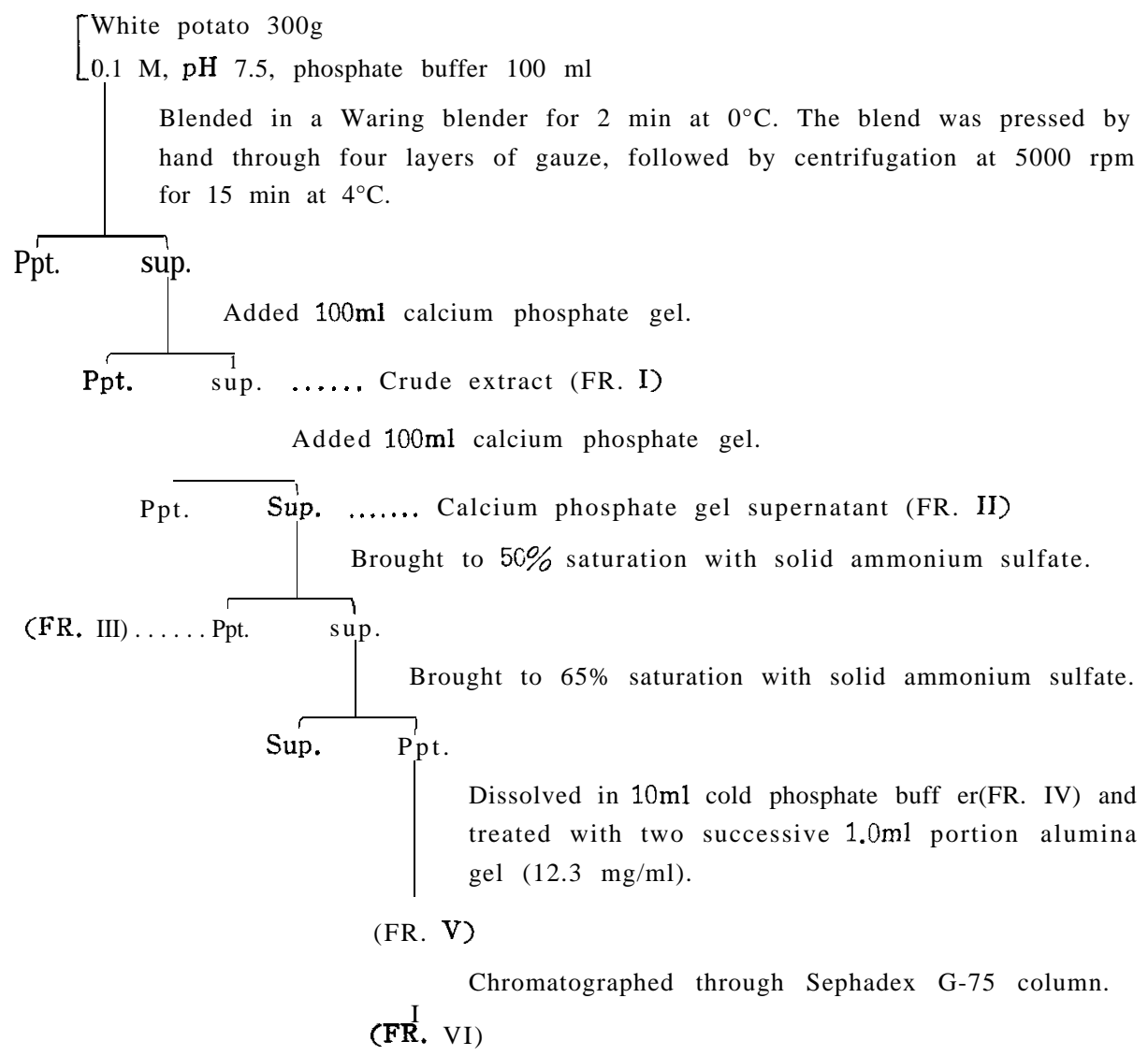

Fig. 1. Preparation of quinone reductase. 


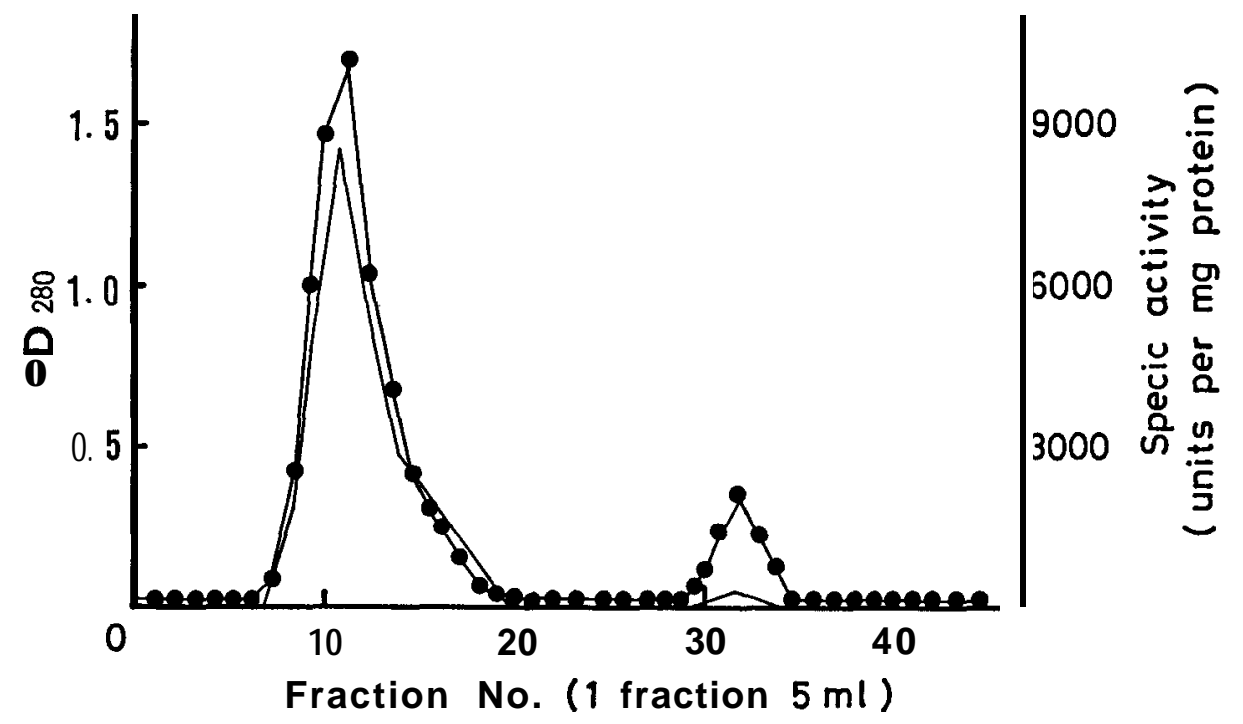

Fig. 2. Chromatography of quinone reductase on Sephadex G-75 column.

- Protein concentration; - Specific activity

Table 1. Summary of purification of quinone reductase.

\begin{tabular}{c|c|c|c}
\hline FR. No. & Total protein $(\mathrm{mg})$ & Total units & Specific activity \\
\hline I Crude extract & 1300 & 585000 & 410 \\
II Calcium phosphate sup. & 1125 & 525000 & 466 \\
III 50\% ppt., (NH,), SO, & 795 & 292500 & 357 \\
IV 65\% ppt.,(NH,) SO, & 15 & 17000 & 1133 \\
V Alumina gel sup. & 8 & 12000 & 1530 \\
VI Sephadex G-75 & & & 8230 \\
\hline
\end{tabular}

quinone reductase.

FR VI, Fig. 2. The protein concentrations and specific activities in the purification process are summarized in Table 1.

Fig. 3 illustrates that quinone reductase significantly catalyzes the oxidation of $\mathrm{NADH}$ by $\mathrm{p}-\mathrm{BQ}$ over that of the non-enzymatic rate.

Such an enzymatic and non-enzymatic reductions of $\mathrm{p}-\mathrm{BQ}$ were demonstrated by Wosilait et al. (1954a) as follows :

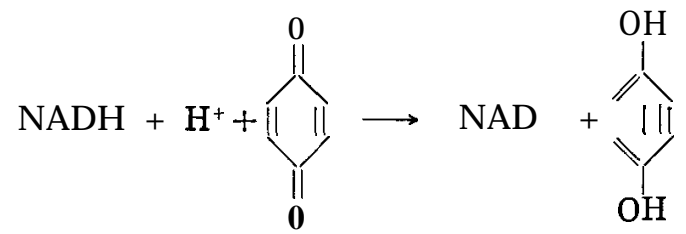

\section{Effect of pH}

The effect of $\mathrm{pH}$ on the enzymatic reaction was determined by using 0.1 $\mathrm{M}$ phosphate buffer at various $\mathrm{pH}$ values. The optimum $\mathrm{pH}$ of this enzyme was 6.5 , but non-enzymatic rate was constant without influence of $\mathrm{pH}$ as shown 


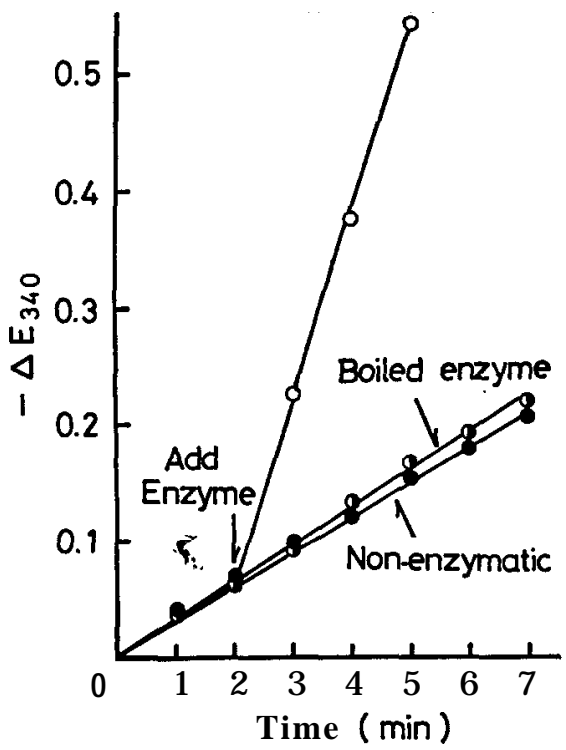

Fig. 3. Comparison of enzymatic and non-enzymatic reaction rate. Enzyme : 120 units.

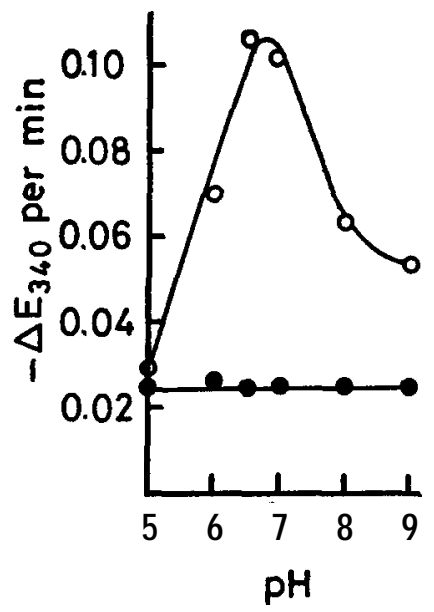

Fig. 4. Effect of pH. Enzyme : 120 units.

$\bigcirc$ Enzymatic ; Non-enzymatic

in Fig. 4. The enzyme was more stable in the alkaline side than in the acidic side.

Dependence of concentration of electron acceptor and electron donor on the enzymatic and non-enzymatic rate

The effect of concentration of $\mathrm{p}-\mathrm{BQ}$ as an electron acceptor on the rate of enzymatic and non-enzymatic reduction is shown in Fig. 5. The typical curves 
have been corrected for non-enzymatic rate. In the same way, the effect of concentration of $\mathrm{NADH}$ as electron donor was investigated. The initial rate of the non-enzymatic and enzymatic oxidations of NADH was directly proportional to the concentration of $\mathrm{NADH}$ as shown in Fig. 6. In the enzymatic reaction, other reducing substances, such as GL, Cy-SH and ASA failed to substitute for $\mathrm{NADH}$.

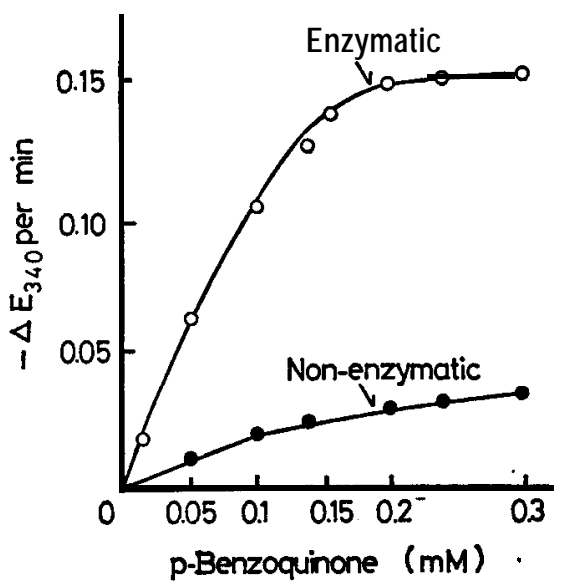

Fig. 5. Effect of p-benzoquinone concentration on the enzymatic and non-enzymatic rate. Enzyme : 110 units.

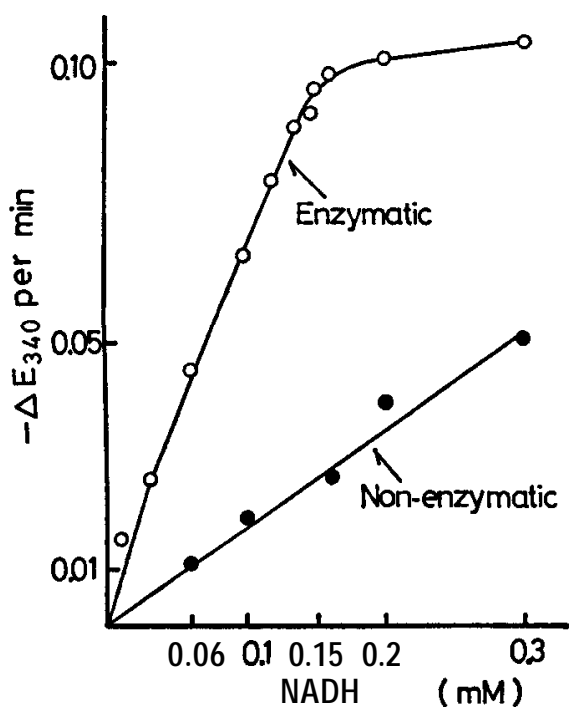

Fig. 6. Effect of NADH concentration on the enzymatic and non-enzymatic rate. Enzyme : 110 units. 


\section{Specificity of electron acceptors}

Various derivatives of $\mathrm{p}-\mathrm{BQ}$ and a-NQ as well as other compounds were tried as possible electron acceptors as shown in Table 2. It appears from the data that the quinones only can serve as acceptors, and another carbonyl compounds are not available as a function in the enzymatic system.

Table 2. Specificity of electron acceptors.

\begin{tabular}{l|c|r}
\hline \multirow{2}{*}{ Substances } & \multicolumn{2}{|c}{$-\Delta \mathrm{E}_{\mathbf{3 4 0}} \mathrm{per} \min \times \mathbf{1 0}^{\mathbf{3}}$} \\
\cline { 2 - 3 } & Non-enzymatic & Enzymatic \\
\hline p-Benzoquinone & 30 & 145 \\
Quinone-N-acetylcysteine & 30 & 155 \\
1,4-Naphthoquinone & 40 & 60 \\
Menadione & 0 & 70 \\
Menadione-N-acetylcysteine & 0 & 145 \\
Pyruvic acid & 0 & 0 \\
Dedngetydascorbic acid & 0 & 0 \\
Cortisone acetate & 0 & 0 \\
\hline
\end{tabular}

It was recognized that there was no consistent relationship between the rate of the enyzmatic and non-enzymatic reaction. The enzymatic and nonenzymatic reaction curves of various quinone derivatives are shown in Fig. 7 and Fig. 8, respectively. In non-enzymatic reaction, p-BQ and QNAC were reduced to the same extent, but MQ and MQNAC were not reduced. On the other hand, four quinones as mentioned above were reduced enzymatically and QNAC was the most readily reduced among all quinones. As shown in Fig. 8, it was interested that the enzymatic reaction rate of the quinones substituted by $\mathrm{N}$ acetylcysteinyl group was larger than that of non-substituted free quinones. In

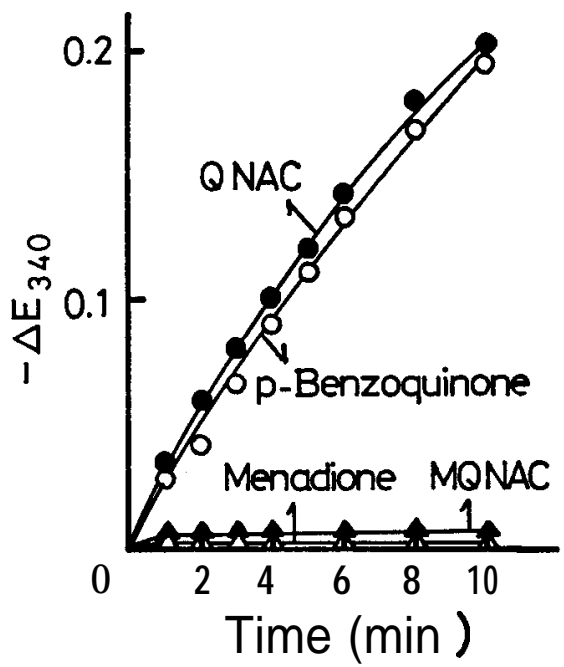

Fig. 7. Difference of non-enzymatic reaction rate between free quinones and their substituted quinones. 


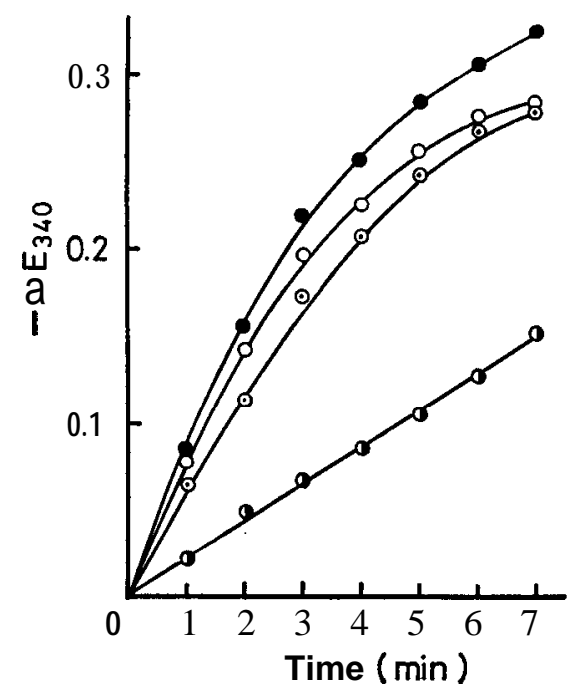

Fig. 8. Difference of enzymatic reaction rate between free quinones and their substituted quinones. Enzyme: 75 units.

p-Benzoquinone ; $\bullet$ Quinone-N-acetylcysteine ;OMenadione; $\odot$ Menadione-Nacetylcysteine

particular, the introduction of $\mathrm{N}$-acetylcysteinyl group to MQ resulted in a remarkable increase in enzymatic reaction rate. These phenomena suggest that the substituted reaction products between the quinones and coexisting SH-compounds in vivo play a specific role in electron transport. However, the reason why the increase in enzymatic rate was brought about by the introduction of $\mathrm{N}$-acetylcysteinyl group to quinone nucleus remains to be solved.

\section{The accelerating effect of the reductones on the enzymatic reaction rate}

After $0.1 \mathrm{ml}$ of various reductones $(7.5 \mathrm{mM})$ was added to $0.15 \mathrm{ml}$ of $\mathrm{MQ}$ NAC ( $4 \mathrm{mM}$ ) and preincubated with bubbling $\mathrm{N}_{2}$ gas for 10 minutes at 20 " $\mathrm{C}$, $0.25 \mathrm{ml}$ of the mixture was used as substrate for enzymatic reaction as mentioned above. The result showed that the enzymatic reaction was accelerated with the reductones and the order of the accelerating effect is MDT>ASA $>$ $\mathrm{TR}>\mathrm{DP}>\mathrm{EP}$, as shown in Fig. 9. In this case, when ASA was preincubated with quinone reductase instead of substrate, MQNAC, the reaction rate was accelerated a little in comparison with control, but not to as great an extent as in the case of ASA-MQNAC. It might suggest that ASA, acting on the substrate, not on the enzyme, transformed the molecular structure to one that was more sensitive to enzymatic reaction. The temperature dependence of such accelerating effect is shown in Fig. 10. MQNAC was incubated with ASA for 10 minutes at various temperatures. The value in figure indicates the difference between decrease in optical density at $340 \mathrm{~m} \mu$ in the presence of ASA and that without ASA. The effect is maximum at $10^{\circ} \mathrm{C}$ and depressed as the temperature rises. 


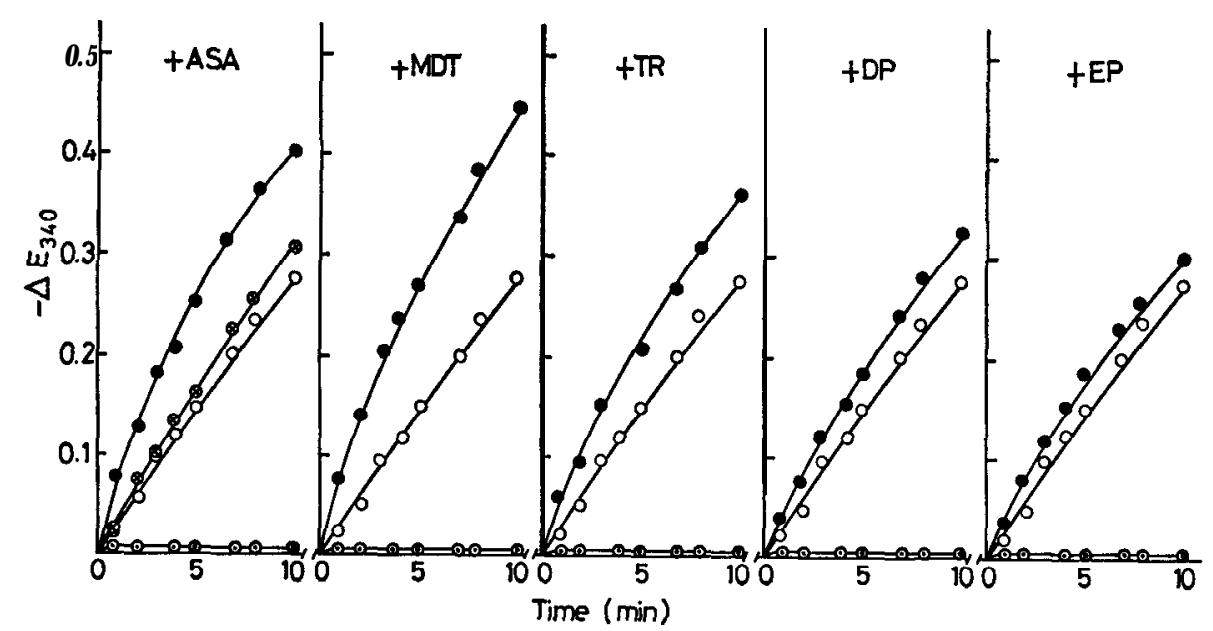

Fig. 9. The accelerating effect of various reductones on the enzymatic reaction rate. The order of accelerating effect : MDT $>A S A>T R>D P>E P$

Non-enzymatic ; Enzymatic (without reductones); Enzymatic (preincubation of MQNAC and reductones); $\otimes$ Enzymatic (preincubation of enzyme and ASA)

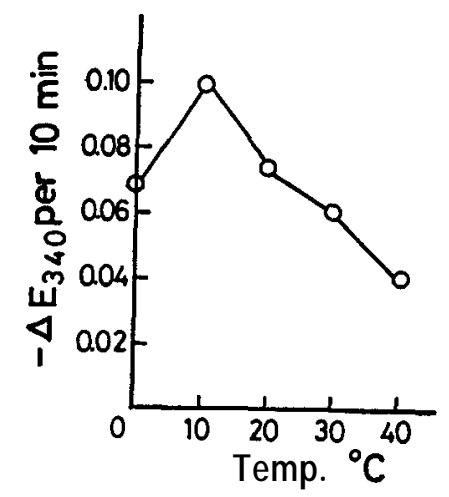

Fig. 10. Temparature dependence of the accelerating effect of ASA. Enzyme : 65 units.

GL and NAC, which are important reducing materials in vivo were investigated to determine whether or not this accelerating effect for enzymatic reaction was specific for enediols. As shown in Fig. 11, GL and NAC had no effect, especially in GL, the reaction rate was suppressed compared with the control. Therefore, it appears that the accelerating effect is specific for enediols. On the other hand, in order to investigate the accelerating effect of reductones when the analogues of MQNAC were used as substrate, MQ and $\alpha-\mathrm{NQ}$ were examined in place of MQNAC. As shown in Table 3, ASA could not accelerate the reaction rate in the system of $\mathrm{MQ}$ and quinone reductase or of a-NQ and quinone reductase. From this fact, it is considered that $\mathrm{N}$-acetylcysteinyl group in MQNAC molecule is closely correlated with such an accelerating effect. Since the enzy- 


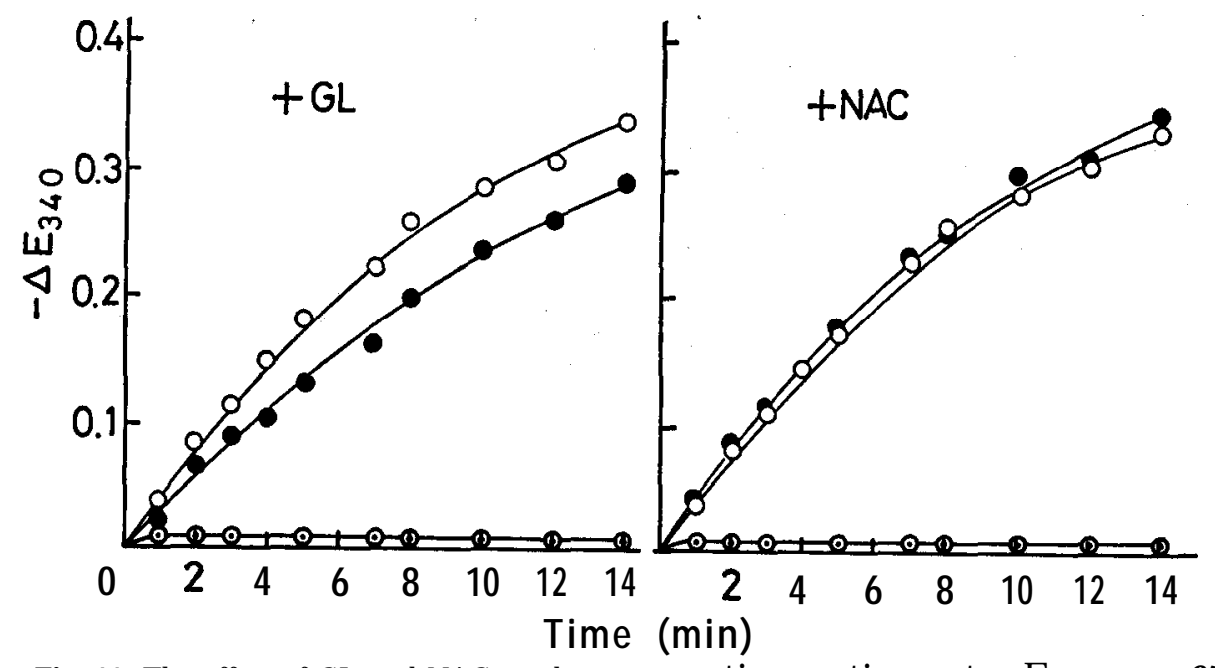

Fig. 11. The effect of GL and NAC on the enzymatic reaction rate. Enzyme : 65 units.

$\odot$ Non-enzymatic; $\bigcirc$ Enzymatic (without SH compounds); $\quad$ Enzymatic (preincubation of MQMAC and SH compounds)

Table 3. The effect of ASA on the enzymatic reduction rate of MQ and a-NQ.

\begin{tabular}{c|cccccccc}
\hline & \multicolumn{1}{c}{$-\Delta \mathrm{E}_{\mathbf{3 4 0}} \times 10^{\mathbf{3}}$} \\
\cline { 2 - 9 } & 1 & 2 & 3 & 4 & 5 & 7 & 8 & 10 \\
\hline MQ only & 50 & 75 & 105 & 130 & 160 & 200 & 220 & 265 \\
$\mathrm{MQ}+$ ASA & 40 & 75 & 100 & 130 & 170 & 210 & 230 & 260 \\
\hline \hline a-NQ only & 50 & 100 & 130 & 160 & 180 & 230 & 240 & 270 \\
$\alpha$-NQ+ ASA & 60 & 115 & 135 & 165 & 195 & 235 & 255 & 275 \\
\hline
\end{tabular}

matic rate was accelerated only in the system of reductones, MQNAC and the enzyme, it was concluded that the accelerating effect was brought about by an interaction between the enediol and $\mathrm{N}$-acetylcysteinyl groups.

Polarographic determination of the accelerating effect in the system of MQNACreductones

The polarograms of various quinones are shown in Fig. 12. The cathodic wave-height of $\mathrm{p}-\mathrm{BQ}, \mathrm{MQ}, \mathrm{MQNAC}$ were the same, respectivly. As the polarographic step of $\mathrm{p}-\mathrm{BQ}$ is two-electron reduction, the step of $\mathrm{MQ}$ and MQNAC is also two-electron, respectively. Half-wave potentials of the substituted quinones were more negative than free quinones. In other words, the substituted quinones were less reducible than free quinones in the dropping mercury electrode. In contrast to this polarographic result, at the enzymatic reduction the substituted quinones were more reducible than free quinones. But the difference between polarographic and enzymatic reduction was not clarified. 


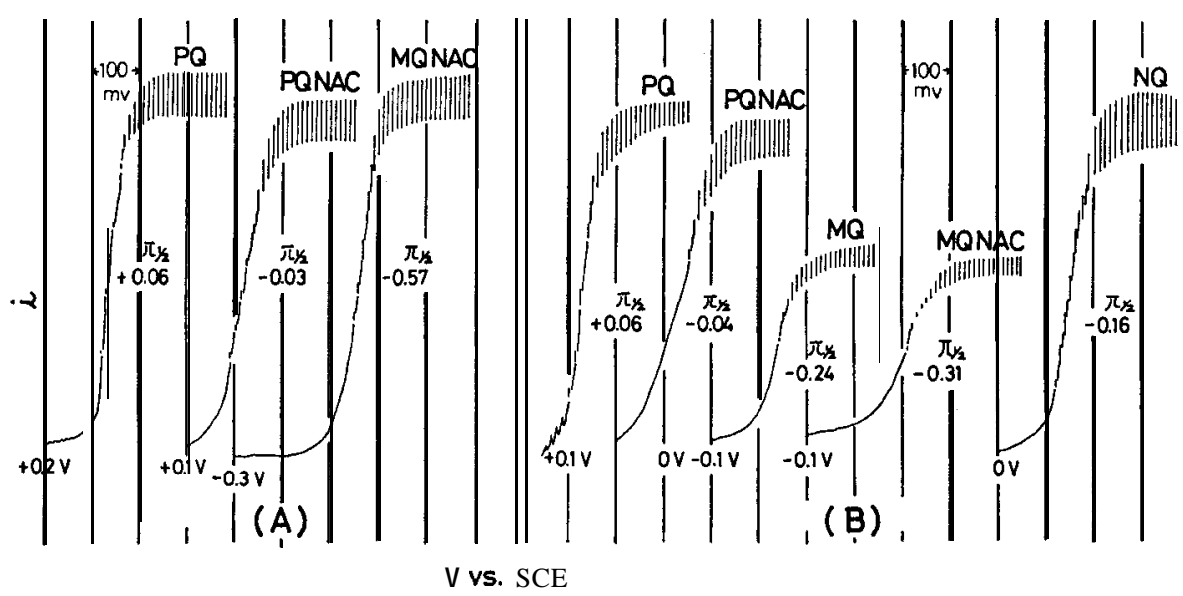

Fig. 12. The polarograms of the various quinones. $\mathrm{A}: 10^{-3} \mathrm{M}$ (in $0.1 \mathrm{M}$, McIlvaine buffer, $\mathrm{pH} 6.5$ ) $\mathrm{B}: 0.2 \times 10^{-3} \mathrm{M}$ (in a solution of $0.1 \mathrm{M}$, Mcllvaine buffer, $\mathrm{pH} 6.5$ and isopropanol in the ratio of $1: 1$ )

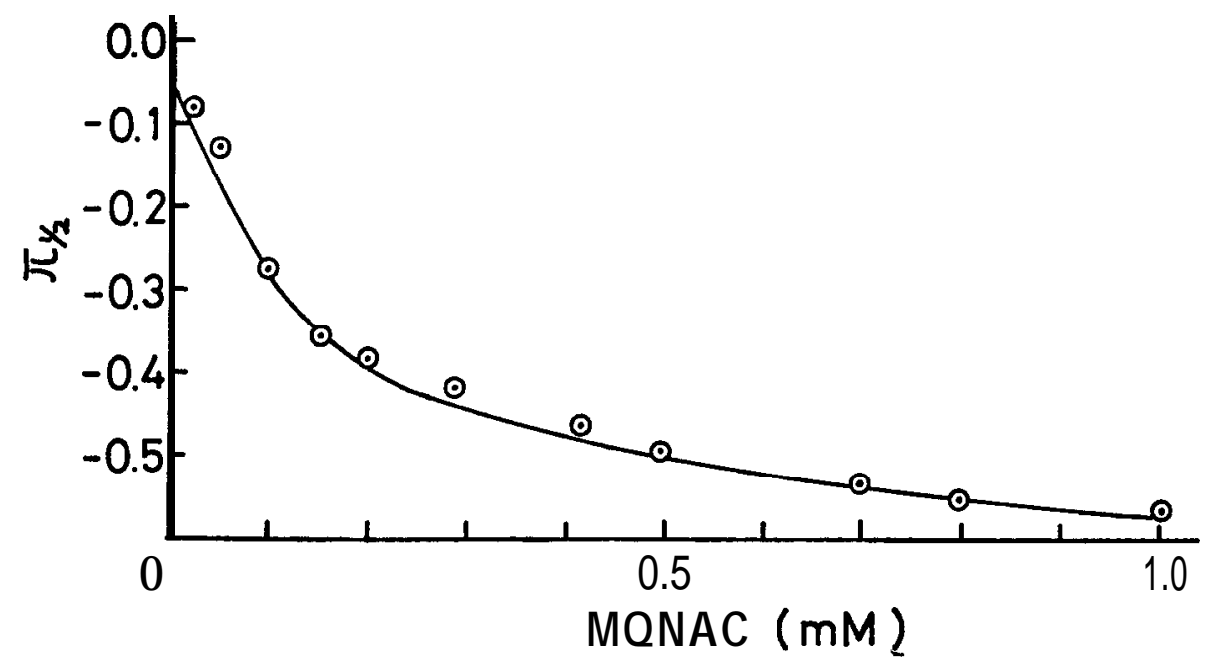

Fig. 13. Changes of the half-wave potential with increasing of concentration of MQNAC.

a) The effect of concentration of MQNAC on the half-wave potential: The halfwave potential of MQNAC was markedly influenced by its concentration as shown in Fig. 13. The half-wave potential of the cathodic wave became more negative with increasing the concentration of MQNAC. Especially, at low concentration below $0.2 \times 10^{-3} \mathrm{M}$, the change of the half-wave potential was remarkable.

From the fact that the half-wave potential of MQNAC is subjected to influence of the concentration of MQNAC, it is considered that MQNAC cannot 
exist as monomer, namely, is transformed gradually to larger molecule with increasing the concentration. The half-wave potential of MQNAC shifts to negative and MQNAC is less reducible owing to this transformation.

b) The influence of reductones on the half-wave potential of MQNAC: The halfwave potential of the cathodic wave of MQNAC was changed by the addition of reductones as shown in Table 4. The half-wave potential of MQNAC shifted

Table 4. The effect of reductones on the half-wave potentials of MQNAC and its related quinones.

\begin{tabular}{|c|c|c|c|c|c|c|c|c|}
\hline & \multirow{2}{*}{ MQNAC only } & \multicolumn{7}{|c|}{ MQNAC } \\
\hline & & $+\mathrm{ASA}$ & $+\mathrm{TR}$ & $+\mathrm{MDT}$ & $+\mathrm{DP}$ & $+\mathrm{EP}$ & $+\mathrm{GL}$ & $+\mathrm{NAC}$ \\
\hline \multirow[t]{2}{*}{$\mathrm{V} \stackrel{\pi_{1}}{\mathrm{vS} .} \mathrm{SCE}$} & -0.39 & -0.13 & -0.13 & -0.16 & -0.33 & -0.35 & -0.40 & -0.37 \\
\hline & MQ only & $\mathrm{MQ}+\mathrm{ASA}$ & $\alpha-\mathrm{NQ}$ & o n l y & \multicolumn{2}{|c|}{$\alpha-\mathrm{NQ}+\mathrm{ASA}$} & & \\
\hline $\begin{array}{c}\pi_{1 / 2} \\
\text { V vs. SCE }\end{array}$ & -0.23 & -0.22 & & -0.15 & \multicolumn{2}{|c|}{0.15} & & \\
\hline
\end{tabular}

to positive side by addition of ASA, TR and MDT, respectively. This indicates that ASA, TR or MDT may disperse MQNAC molecule aggregated by a sort of electrostatic bond to smaller molecule. When ASA was added to free quinones such as $\mathrm{MQ}$ and a-NQ which are analogues of MQNAC, the half-wave potential of MQ and $\alpha-\mathrm{NQ}$ were almost the same as the value of MQ and $\alpha$-NQ themselves. That was to say, ASA had no effect on the half-wave potential of $\mathrm{MQ}$ and $\alpha$-NQ. It is understood from this fact that $\mathrm{N}$-acetylcysteinyl group has some influences on the shift of half-wave potential of MQNAC. In addition, SH-compouds, such as GL and NAC were investigated to determine whether or not the shifting effect of the reductones was only due to their reducing ability. GL and NAC could not cause the shift of half-wave potential of MQNAC as shown in Table 4.

Since the shift of the half-wave potential is observed only in the combination of MQNAC and the reductones, the shift is presumably brought about by interaction between enediol groups and $\mathrm{N}$-acetylcysteinyl group as shown in the case of the accelerating effect in enzymatic reaction.

The shift of half-wave potintial of MQNAC to positive as observed in polarogram is closely related to an accelerating effect in enzymatic reaction rate, that is, the substances which have a shifting effect on the half-wave potential are able to accelerate the enzymatic reaction rate in the system of $\mathrm{MQ}$ NAC-quinone reductase.

It is concluded from the data mentioned above that the free quinones are substituted by $\mathrm{N}$-acetylcysteinyl group and their corresponding substituted quinones, for example, QNAC and MQNAC are more readily reduced by enzyme than the free quinones, therefore, that the polymerization of free quinones is much depressed. 
Furthermore, in the case of MQNAC as a substrate, the reductones such as ASA, TR and MDT accelerate its enzymatic reaction rate. If these phenomena can be applied to the enzymatic browning reaction, it may be said that the enzymatic browning is much depressed by a transformation of the quinones produced in the course of enzymatic browning to the quinones substituted by $\mathrm{SH}$ compounds, such as $\mathrm{N}$-acetylcysteine. As the reductones accelerate the enzymatic reaction rate, the browning is further depressed by these substances.

\section{REFERENCES}

Bayer, E., F. Born and K. H. Reuther 1957 The polyphenol oxidase of grapes. Chem. A str., $51: 7644 \mathrm{~g}$ (1957)

Bruemmer, J. H., and B. Roe 1970 Enzymatic oxidation of simple diphenols and flavonoids by orange juice extract. J. Food Sci., 35: 116

Gladilovich, B. R., and R. I. Drel 1965 Influence of Phytophthora infection on the chemical composition of tomato plants. Chem. Abstr. 64: 11564c (1966)

Hatanaka, C., D. Nomura and H. Omura 1972a Studies on the indophenol reducing substances in the reaction system of p-benzoquinone and amino acid. Nippon Nogeikagaku Kaishi 46: 341

Hatanaka, C., D. Nomura and H. Omura 1972b Studies on the reaction products of menadione and N-acetylcysteine. Nippon Nogeikagaku Kaishi $46: 525$.

Hulme, A. C. 1958 Some aspects of the biochemistry of apples and pear fruits. Advan. Food Res., $8: 297$

Lazzarini, R. A., and A. S. Pietro 1964 A nonspecific pyridine nucleotide diaphorase from spinach. Arch. Biochem. Biophys., $106: 6$

Lowry, 0. H., N. J. Rosebrough, and A. L. Farr 1951 Protein measurement with the Folin phenol reagent. J.Biol. Chem., $193: 265$

Mason, H. S. 1955 Reaction between quinones and proteins. Nature (London) 175 :771

Mason, H. S., and E. W. Peterson 1965 Melanoproteins. 1. Reaction between enzyme-generated quinones and amino acids. Biochem. Biophys. Acta $111: 134$

Nomura, D., and H, Omura 1969 Chemie der Reductone. Uchida Rokakuho Publishing Co., LTD., Tokyo

Palmer, J. K. 1963 Banana polyphenol oxidase : Preparation and properties. Plant Physiol.: $38: 508$

Patel, S. S., and M. Zucker 1965 Potato phenolase : Purification and properties. J. Biol. Chem., $240: 3938$

Reyes, P., and B. S. Luh 1960 Characteristics of browning enzymes in Fay Elberta freestone peaches. Food Technol., (Chicago) 14: 570

Sanderson, G. W. 1964 Extraction of soluble cathechol oxidase from tea shoot tips. Biochim. Biophys. Acta, $92: 622$

Wosilait, W. D., A. Nason 1954a Pyridine nucleotide-quinone reductase. 1. Purification and properties of the enzyme from pea seeds. J. Biol. Chem., $206: 255$

Wosilait, W. D., A. Nason, and A. J. Terre11 1954b Pyridine nucleotide-quinone reductase. 2. Role in electron transport. J. Biol. Chem., $206: 271$ 